\title{
Minimally invasive ablation of a migrating focus of inappropriate sinus tachycardia
}

\author{
Thomas M. Beaver, MD, MPH, ${ }^{\mathrm{a}}$ William M. Miles, MD, ${ }^{\mathrm{b}}$ Jamie B. Conti, MD, ${ }^{\mathrm{b}}$ Alex Kogan, BS, ${ }^{\mathrm{d}}$ \\ Thomas A. Burkart, MD, ${ }^{\mathrm{b}}$ Gregory W. Woo, MD, ${ }^{\mathrm{c}}$ and Sherry J. Saxonhouse, MD, ${ }^{\mathrm{b}}$ Gainesville, Fla, and \\ Westchester, Ohio
}

\section{CLINICAL SUMMARY}

A 31-year-old echocardiography technician experienced tachycardia after pregnancy 3 years before presentation. The patient reported symptoms of dizziness, shortness of breath, and fatigue. An echocardiogram revealed an ejection fraction of $65 \%$ and mild mitral valve prolapse. Twentyfour-hour Holter monitoring showed a resting heart rate between 70 and 175 beats/min with rare premature ventricular complexes and rare atrial premature complexes with no evidence of sinoatrial or atrioventricular nodal block. Metoprolol, atenolol, sotalol, digoxin, and amiodarone therapy had failed. Prior catheter-based ablation attempts had mapped the focus of tachycardia laterally at the superior vena cava and right atrial junction. The catheter ablation attempts were able to modify the heart rate; however, they were aborted because of proximity of the right phrenic nerve.

Subsequently, she was referred for a minimally invasive thoracoscopic isolation of the sinus node using a dry bipolar radiofrequency energy clamp (AtriCure, West Chester, Ohio). ${ }^{1,2}$ Port sites were placed at the fifth interspace in the anterior axillary line and the sixth interspace in the posterior axillary line, and a 5-cm incision was made in the mid-axillary third interspace. The pericardium was opened, and adhesions from the catheter ablations were found lateral to the superior vena cava in the vicinity of the phrenic nerve. An isoproterenol infusion $(4 \mu \mathrm{g} / \mathrm{min})$ was started, which elevated the resting heart rate to 140 beats $/ \mathrm{min}$. The superior vena cava was then dissected free and the entire sinoatrial node complex was encircled with the radiofrequency clamp, which was applied multiple times with no change in the resting heart rate, although pacing confirmed transmural ablation lines (Figure 1).

Subsequently, a reference electrode was sutured medial to the superior vena cava at the right atrial junction (Figure 2),

From the Division of Cardiovascular Surgery, ${ }^{\mathrm{a}}$ Electrophysiology, ${ }^{\mathrm{b}}$ and Cardiology, ${ }^{\mathrm{c}}$ University of Florida College of Medicine, Gainesville, Fla; and Atricure Corporation, ${ }^{\mathrm{d}}$ Westchester, Ohio.

Disclosures: None.

Received for publication Dec 27, 2008; accepted for publication Jan 2, 2009; available ahead of print March 20, 2009.

Address for reprints: Thomas M. Beaver, MD, MPH, Associate Professor, Division of Thoracic and Cardiovascular Surgery, University of Florida College of Medicine, PO Box 100286, Gainesville, FL 32610-0286 (E-mail: beavetm@surgery.ufl.edu). J Thorac Cardiovasc Surg 2010;139:506-7

$0022-5223 / \$ 36.00$

Copyright (c) 2010 by The American Association for Thoracic Surgery doi:10.1016/j.jtcvs.2009.01.002 and a thoracoscopic bipolar pen electrode (Isolator pen, AtriCure) that senses local electrograms and performs ablations was used for intraoperative activation mapping. Epicardial activation mapping was performed by comparing electrograms from the isolator pen with the reference electrode (sewn onto the atrium) and the onset of the $\mathrm{P}$ wave on the lead II body surface electrocardiogram. The pen identified the site of the earliest activation had migrated down the right atrium, which was then ablated epicardially with the same pen (energy level 10-20W for 40 seconds). However, repeat mapping showed the focus had now migrated further down the right atrium, requiring repeat mapping and ablations at several more sites (Figure 2). As the inciting focus migrated toward the inferior vena cava, the resting heart rate (with isoproterenol infusion) eventually decreased from approximately 140 to 110 beats/min, and the $\mathrm{P}$ waves on the lead II body surface electrocardiogram became inverted. Port sites were then closed, and the patient was discharged with a chest $\mathrm{x}$-ray demonstrating preservation of the phrenic nerve. Twenty-four-hour Holter monitoring performed 1 month later showed the baseline rhythm was in the 70s, and the patient reported relief from her tachycardia.

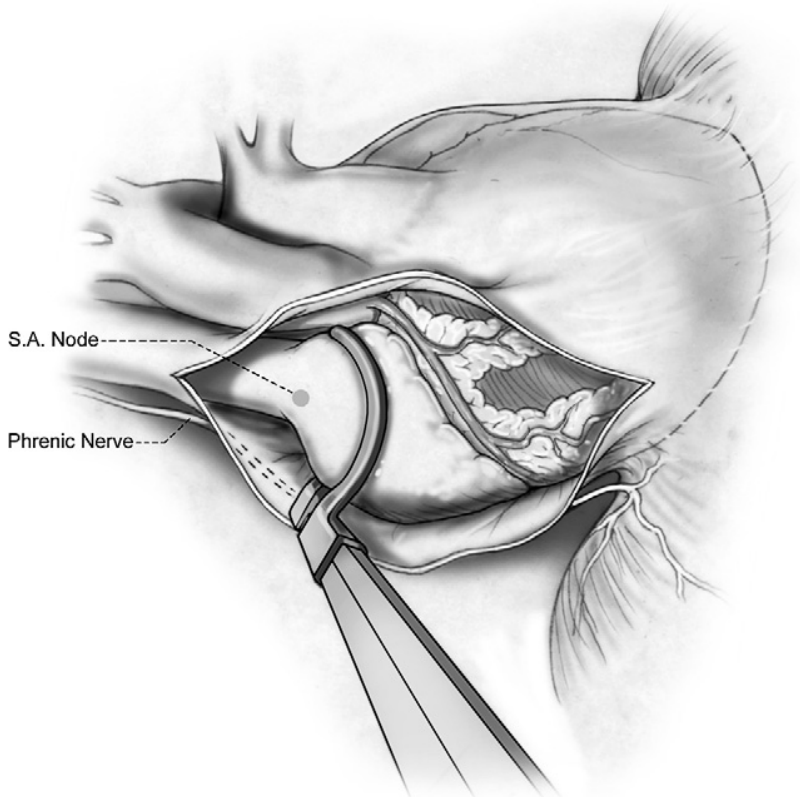

FIGURE 1. Bipolar radiofrequency energy clamp isolating the sinoatrial node (S.A.) complex for inappropriate sinus tachycardia safely away from the phrenic nerve. 


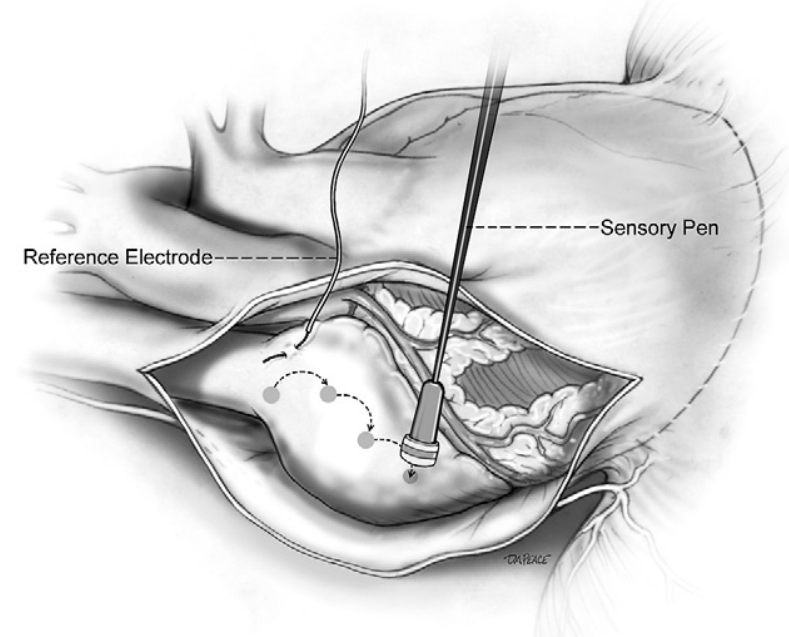

FIGURE 2. Thoracoscopic sensing, pacing, and ablation electrode used to map a migrating focus of tachycardia; the focus migrates, requiring repeat ablations.

\section{DISCUSSION}

Inappropriate sinus tachycardia is challenging for the electrophysiology community because the ablation targets are often located proximal to the phrenic nerve, occasionally resulting in phrenic nerve injury. ${ }^{3-5}$ Video-assisted ablation is a safe alternative that preserves the phrenic nerve. ${ }^{1,2}$

Persistence of inappropriate sinus tachycardia secondary to migration of the earliest site of activation is known to electrophysiologists; however, it may not be known to cardiothoracic surgeons. ${ }^{5}$ Younger surgeons also may not be familiar with activation mapping, which uses a roving sens- ing electrode to compare electrograms from various sites on the atrium with the body surface electrocardiogram $\mathrm{P}$ wave (lead II) and a reference electrode (the wire sutured to the right atrial appendage). The thoracoscopic bipolar pen showed that the earliest site of activation was migrating down the atrium, although it was eventually ablated. Man and colleagues ${ }^{4}$ reported 13 of 22 patients in the catheterization laboratory had a cranial to caudal migration of their activation sites with an eventual abrupt change in P-wave morphology. Marrouche and colleagues ${ }^{5}$ used a 3-dimensional mapping system in the catheterization suite and found that that the inciting focus of tachycardia shifted caudally an average of $23 \pm 11 \mathrm{~mm}$ after ablation. ${ }^{5}$

\section{CONCLUSIONS}

This case describes a migrating focus of inappropriate sinus tachycardia and demonstrates that it can be mapped and ablated by surgeons epicardially with the use of a thoracoscopic pen electrode.

\section{References}

1. Taketani T, Wolf RK, Garrett JV. Partial cardiac denervation and sinus node modification for inappropriate sinus tachycardia. Ann Thorac Surg. 2007;84:652-4.

2. Kreisel D, Bailey M, Lindsay BD, Damiano RJ Jr. A minimally invasive surgical treatment for inappropriate sinus tachycardia. J Thorac Cardiovasc Surg. 2005; 130:598-9.

3. Vatasescu R, Shalganov T, Kardos A, Jalabadze K, Paprika D, Gyorgy M, et al Right diaphragmatic paralysis following endocardial cryothermal ablation of inappropriate sinus tachycardia. Europace. 2006;8:904-6.

4. Man KC, Knight B, Tse HF, Pelosi F, Michaud GF, Flemming M, et al. Radiofrequency catheter ablation of inappropriate sinus tachycardia guided by activation mapping. J Am Coll Cardiol. 2000;35:451-7.

5. Marrouche NF, Beheiry S, Tomassoni G, Cole C, Bash D, Dresing T, et al. Threedimensional nonfluoroscopic mapping and ablation of inappropriate sinus tachycardia. Procedural strategies and long-term outcome. J Am Coll Cardiol. 2002; 39:1046-54.

\title{
Left atrioesophageal fistula following catheter ablation for atrial fibrillation: Off-bypass, primary repair using an extrapericardial approach
}

\author{
Sandeep Khandhar, MD, Stephanie Nitzschke, MD, and Niv Ad, MD, Falls Church, Va
}

\footnotetext{
From the Inova Heart and Vascular Institute, Falls Church, Va.

Disclosures: None.

Received for publication Dec 17, 2008; accepted for publication Dec 27, 2008; available ahead of print March 18, 2009.

Address for reprints: Niv Ad, MD, Inova Heart and Vascular Institute, 3300 Gallows

Rd, Falls Church, VA 22042 (E-mail: nivadmd@hotmail.com).

J Thorac Cardiovasc Surg 2010;139:507-9

$0022-5223 / \$ 36.00$

Copyright (c) 2010 by The American Association for Thoracic Surgery

doi:10.1016/j.jtcvs.2008.12.036
}

Catheter ablation for the treatment of atrial fibrillation is becoming the treatment of choice for drug-refractory symptomatic atrial fibrillation. This technique has increased in popularity, and the number of cases performed each year has risen dramatically. ${ }^{1}$ Although widely utilized, the technique of catheter ablation varies widely among electrophysiology labs. ${ }^{1}$ Overall, this procedure is considered safe, with the incidence of significant complications at $6 \% .^{1}$ This 